\title{
Spatiotemporal Maps of Brain Activity Underlying Word Generation and Their Modification during Repetition Priming
}

\author{
Rupali P. Dhond, ${ }^{1,2}$ Randy L. Buckner, ${ }^{3}$ Anders M. Dale, ${ }^{2}$ Ksenija Marinkovic, ${ }^{2}$ and Eric Halgren ${ }^{1,2}$ \\ ${ }^{1}$ Department of Radiology, University of Utah, Salt Lake City, Utah 84105, 2Nuclear Magnetic Resonance Center, \\ Massachusetts General Hospital, Charlestown, Massachusetts 02129, and 3Department of Psychology, Radiology, and \\ Anatomy and Neurobiology, Howard Hughes Medical Institute, Washington University, St. Louis, Missouri 63130
}

Spatiotemporal maps of brain activity based on magnetoencephalography were used to observe sequential stages in language processing and their modification during repetition priming. Subjects performed word-stem completion and produced either novel or repeated (primed) words across trials. Activation passes from primary visual cortex (activated at $\sim 100 \mathrm{msec}$ after word presentation), to left anteroventral occipital ( $\sim 180$ msec), to cortex in and near Wernicke's ( $210 \mathrm{msec})$ and then Broca's ( $\sim 370 \mathrm{msec})$ areas. In addition, a posteroventral temporal area is activated simultaneously with posterosuperior temporal cortex. This area shows an early $(\sim 200-245 \mathrm{msec})$ increase in activation to repeated word stems. In contrast, prefrontal and anterior temporal regions showed activity reductions to repeated word stems late $(\sim 365-500 \mathrm{msec})$ in processing. These results tend to support classical models of language and suggest that an effect of direct item repetition is to allow word-form processing to increase its contribution to task performance while concurrently allowing reductions in timeconsuming frontal temporal processing.

Key words: word-stem completion; magnetoencephalography; temporal lobe; planum temporale; prefrontal cortex; language; occipital lobe; word form
Lesion-based studies of language provide a general framework for interpreting brain activation during verbal processing. In the classical Wernicke-Geschwind model of language, seen words acquire meaning only after conversion into a phonological image (i.e., only after entering the same stream as heard words) (Geschwind, 1965; Benson, 1979). This model proposes that initial visual processing in occipital cortex is followed by grapheme to phoneme conversion mediated by the left angular and supramarginal gyri. Afterward, lexical access occurs in left posterosuperior temporal cortex (classically defined "Wernicke's area"). Left posteroventral prefrontal cortex (classically defined "Broca's area") is recruited last and may subserve syntax and verbal production.

This influential but incomplete early model was based on language deficits produced by brain lesions (Benson, 1979). Positron emission tomography (PET) and functional magnetic resonance imaging (fMRI) permit hemodynamic changes associated with processing of visually presented words to be mapped in normal subjects. In addition to the classical language areas (Howard et al., 1992; Pujol et al., 1996; Phelps et al., 1997; Thompson-Schill et al., 1999), such studies commonly find activation in occipital (Petersen et al., 1988, 1989, 1990; Binder, 1997) and medial frontal (Fiez and Petersen, 1998) areas. Finally, language-related activation to visual words has been found in basal temporal areas with intracranial event-related potentials (iERPs) (Smith et al., 1986; Halgren et al., 1994a; Nobre and

\footnotetext{
Received Sept. 14, 2000; revised Feb. 28, 2001; accepted Mar. 2, 2001.

This work was supported by the United States Public Health Service [National Institutes of Health (NIH) Grant NS18741], by the National Foundation for Functional Brain Imaging (Department of Energy Grant DE-FG03-99ER62764), and by NIH Grant MH57506. We thank Bruce Fischl, Arthur Liu, Thomas Witzel, Jeff Lewine, Bruce Rosen, and David Caplan.

Correspondence should be addressed to Dr. Eric Halgren, Massachusetts General Hospital, Nuclear Magnetic Resonance Center, Room 2301, Building 149, 13th Street, Charlestown, MA 02129. E-mail: halgren@nmr.mgh.harvard.edu. Copyright (C) 2001 Society for Neuroscience $0270-6474 / 01 / 213564-08 \$ 15.00 / 0$
}

McCarthy, 1995), and electrical stimulation in these areas can cause specific language deficits (Burnstine et al., 1990; Luders et al., 1991). Collectively, these studies build an understanding of the network of brain areas that subserve language processing.

To accurately characterize higher cognitive functions such as language, however, knowledge about the timing and sequence of responses is also needed. For example, activity within anterior occipital cortex could be associated with word-form encoding only if it occurs early. Conversely, medial frontal activation may be involved in response organization, so recruitment of these areas should occur relatively late. Activity in posteroventral prefrontal cortex, near classically defined Broca's area, is ubiquitous and could be related to an earlier process, such as lexical or semantic access, rather than to response production as suggested in classical models.

Although fMRI and PET have good spatial resolutions, their temporal resolutions are inadequate to sequence language-related brain activity. iERPs provide accurate temporal and spatial resolution but only in limited areas in patients with brain disease. The current study uses magnetoencephalography (MEG) to map language-related activation in normal subjects with excellent temporal resolution and adequate spatial resolution (Dale et al., 2000). A word-stem completion task requiring word generation was chosen because it has been well studied hemodynamically (Squire et al., 1992; Buckner et al., 1995; Schacter et al., 1996; Ojemann et al., 1998). Furthermore, presenting just parts of words would be expected to prevent immediate lexical access and thus allow the successive stages to be more clearly distinguished. Within the word-stem completion task, repetition priming was used to help separate different aspects of language processing.

\section{MATERIALS AND METHODS}

Stem completion task. Eight normal right-handed males viewed centrally presented three-letter word stems projected onto a screen to subtend a $<5 \%$ visual angle. Using Mac Probe software (Hunt, 1994), word stems 
were presented in Geneva font as white letters on a black background. Subjects were shown 224 word stems, with seven word stems repeated randomly throughout the experiment. Each repeated word stem was shown 15 times. Word stems were presented for $250 \mathrm{msec}$, and stimulus onset asynchrony was $2.3 \mathrm{sec}$. The stimulus list was the same as that used in previous fMRI studies (Buckner et al., 2000) and consisted of word stems that were selected from a pool of 288 unique three-letter word stems that each had at least five English word completions. Between word-stem presentations, subjects fixated on a "+" sign in the center of the screen. Word stems consisted of all capital letters (i.e., "GRE"). Subjects were given a study block before the experiment in which they generated words to a set of 42 word stems. Seven word stems were repeated randomly six times and were the same "repeated" word stems used during the actual experiment. For the experimental phase, subjects were required to silently generate words that began with the presented word stems. Subjects were told not to generate words that were proper nouns.

Silent generation was requested to prevent artifacts because of movement of oral musculature. Subjects were experienced in MEG experiments and had been selected on the basis of reliability and compliance with instructions. Data from previous studies using similar covert generation procedures indicates behavioral priming highly similar to that obtained from overt stem completion and that covert stem completion evokes robust fMRI responses, including frontal temporal language areas (Buckner et al., 2000).

$M E G$ recording. MEG signals were recorded from 204 channels at 0.1-100 Hz using a Neuromag instrument (4D Neuroimaging, San Diego, CA) with orthogonal pairs of planar gradiometers at each of 102 locations over the entire scalp. Separate averages of novel and repeated word-stem completion trials were constructed for each subject after rejecting trials with eyeblinks or other artifacts using amplitude criteria confirmed with visual inspection. Head movement was minimized using a chinstrap and foam padding on the sides of the head.

Cortical surface reconstruction. Geometrical representations for the cortical surfaces of each subject were obtained using procedures described previously (Dale and Sereno, 1993; Dale et al., 1999; Fischl et al., 1999). First, high-resolution three-dimensional T1-weighted structural images were acquired for each subject using a 1.5T Picker Eclipse (Marconi Medical, Cleveland, OH). Next, the cortical white matter was segmented and the estimated border between gray and white matter was tessellated, providing a topologically correct representation of the surface with $\sim 150,000$ vertices per hemisphere. For the inverse computation, the cortical surface was decimated to $\sim 3000$ dipoles per hemisphere, which is approximately equivalent to one dipole every $10 \mathrm{~mm}$ along the cortical surface. Finally, the folded surface tessellation was "inflated" to unfold cortical sulci, thereby providing a convenient format for visualizing cortical activation patterns (Dale and Sereno, 1993; Dale et al., 1999; Fischl et al., 1999). For purposes of intersubject averaging, the reconstructed surface for each subject was morphed into an average spherical representation, optimally aligning sulcal and gyral features across subjects but minimizing metric distortions (Fischl et al., 1999).

Forward solution. The boundary element method was used to calculate the signal expected at each MEG sensor, for each dipole location (deMunck, 1992; Oostendorp and Van Oosterom, 1992). The computation of the MEG forward solution has been shown to only require the inner skull boundary to achieve an accurate solution (Meijs and Peters, 1987; Meijs et al., 1987; Hamalainen and Sarvas, 1989).

The MEG sensor coordinate system was aligned with the MRI coordinate system using three head position (HPI) coils attached to the scalp (Hamalainen et al., 1993). The HPI coils generate weak magnetic signals and thus can be directly localized by the MEG sensors. The positions of the HPI coils with respect to the subject's head (and thus MRI) were determined by measuring multiple points (including the HPI coils) using a Polhemus FastTrack three-dimensional digitizer (Polhemus, Colchester, VT).

Inverse solution. To estimate the time courses of cortical activity, the noise-normalized, anatomically constrained linear estimation approach described by Dale et al. (2000) was used. This approach is similar to the generalized least-squares or weighted minimum norm solution (Hamalainen and Ilmoniemi, 1984; Dale and Sereno, 1993), but the estimate is normalized for noise sensitivity (Dale et al., 2000). The noise normalization has the effect of greatly reducing the variation in the point-spread function between locations. This approach provides statistical parametric maps of cortical activity, similar to the statistical maps typically generated using fMRI or PET data but with a temporal resolution of 5 msec or better.

Because no a priori assumptions were made about the local dipole orientation in the current study, three components are required for each location. A sensitivity-normalized estimate of the local current dipole power (sum of squared dipole component strengths) at location $i$ is given by

$$
q_{\mathrm{i}}(t)=\frac{\sum_{j \in G_{\mathrm{i}}}\left(w_{\mathrm{j}} \cdot x(t)\right)^{2}}{\sum_{j \in G_{\mathrm{i}}} w_{\mathrm{j}} C w_{\mathrm{j}}^{\mathrm{T}}},
$$

where $G_{\mathrm{i}}$ is the set of (three) dipole component indices for the $i$ th location, and $w_{\mathrm{i}}$ denotes the $i$ th row of the inverse operator $w$ (Dale and Sereno, 1993; Liu et al., 1998; Dale et al., 2000). Note that, under the null hypothesis, $q_{\mathrm{i}}(t)$ is $F$-distributed, with three degrees of freedom for the numerator. The degrees of freedom for the denominator are typically large, depending on the number of time samples used to calculate the noise covariance matrix $C$. For the novel and repeated word stems, significance thresholds were set at $p<10^{-8}$, with a full red response indicating $p<10^{-11}$ and $p<10^{-17}$, indicating peak activation with a bright yellow color. For dynamic statistical parametric maps of novelrepeat subtractions, thresholds were $p<10^{-5}, p<10^{-7}$, and $p<10^{-12}$, respectively.

In summary, noise sensitivity-normalized cortical surface-constrained minimum norm inverse solutions were calculated every $5 \mathrm{msec}$ for every condition and every individual. These movies were then averaged on the cortical surface across individuals after aligning their sulcal-gyral patterns.

\section{RESULTS}

\section{Generating words to novel word stems}

Novel word stems evoked a robust left-lateralized MEG signal (Fig. 1). The response followed a posterior-to-anterior sequence of cortical recruitment involving visual processing areas, regions near classical language areas, and other sites (Fig. 2). The earliest activation was bilateral, first in the occipital pole (from $\sim 100$ to $125 \mathrm{msec}$ ) (Fig. 2) and then in ventroanterior occipital regions (from $\sim 125$ to $145 \mathrm{msec}$ ) (Fig. 2). Activity was then lateralized to the left ventroanterior occipital cortex beginning at $\sim 150 \mathrm{msec}$, becoming clearly lateralized from $\sim 165$ to $190 \mathrm{msec}$ (Fig. 2). Activity remained strongly biased to the left hemisphere during all subsequent time intervals.

A progressive posterior-to-anterior shift of activation followed the early ventral occipital responses. This shift began at $\sim 195$ msec, and by $\sim 205-230 \mathrm{msec}$, activity was prominent in posterior temporal regions, including the planum temporale by $\sim 210 \mathrm{msec}$, as well as posterior segments of the superior, middle, and inferior temporal gyri, extending to include the fusiform gyrus (Fig. 2).

In the 235-365 msec period, the response progressed further anteriorly, encompassing lateral anterior temporal cortex and insulo-opercular regions (Fig. 2). Activity mainly involved the superior temporal sulcus and then extended broadly to include middle and anterior levels of the superior temporal sulcus, the temporal pole, posteroventral prefrontal cortex, and collateral sulcus. On the ventral surface of the temporal lobe, activation was most prominent in the inferior temporal gyrus and lateral occipitotemporal sulcus but continued to include the fusiform gyrus. Although not shown, activation became briefly focal in the left planum temporale at $300 \mathrm{msec}$.

Finally, from $\sim 365$ to $415 \mathrm{msec}$ (Fig. 2), responses were strongest in the planum temporale, anterior temporal cortex (laterally and ventrally), and inferior prefrontal regions. The prefrontal activation was most prominent in the inferior frontal gyrus, pars opercularis, including the pars triangularis, as well as orbital cortex. The same regions remained activated until after $500 \mathrm{msec}$; 


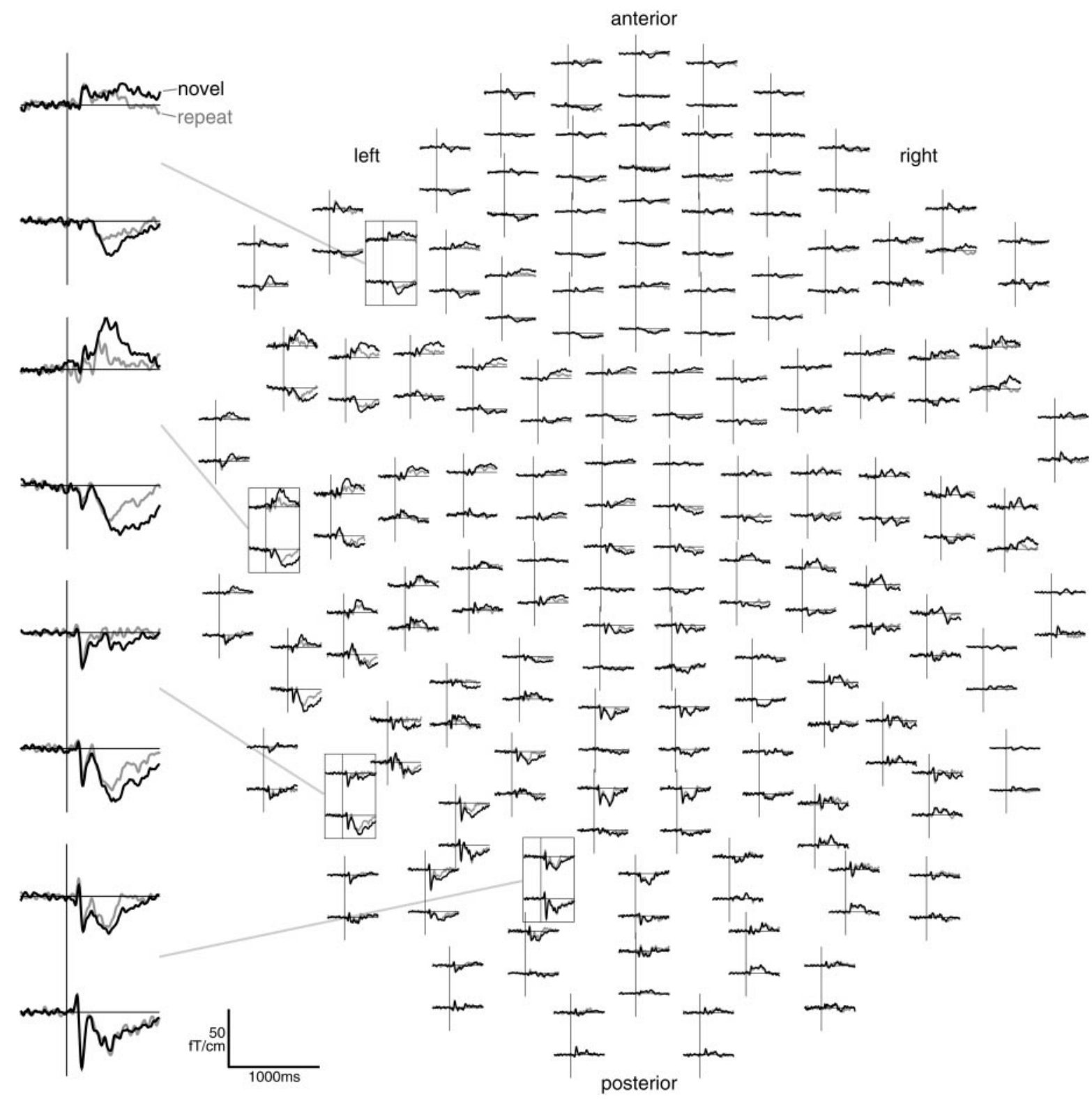

Figure 1. Sample waveforms. MEG waveforms from all 204 channels in one subject in response to novel (black lines) and repeated (gray lines) word stems. Signals from four pairs of gradiometers are shown in expanded format on the left.

in addition, after $\sim 415 \mathrm{msec}$, activity was again seen in posteroventral temporal cortex. After $470 \mathrm{msec}$, activity became more bilateral, again involving mainly orbital and ventral occipitotemporal cortex on the right. Inferior prefrontal and anterior temporal activation was still apparent at $510 \mathrm{msec}$. Although some activation was visible for $>1000 \mathrm{msec}$ in some individuals (Fig. 1), in the group average, activity was minimal by $\sim 550 \mathrm{msec}$.

\section{Repetition effects}

Activation movies were made from the MEG waveforms obtained by subtracting the waveforms evoked by the repeated word stems from those evoked by the novel word stems (Fig. 3). Activation present in the novel-minus-repeated movies indicates significant power in the difference waveform between these conditions at the indicated latency and estimated location. Because power is not a signed quantity, a single movie cannot be used to infer which condition had greater absolute activation at any particular location and time. Instead, the direction of that difference (i.e., which condition had greater absolute activation at that particular location and time) can only be inferred by comparing the activations in the nonsubtracted novel and repeated movies. In making these comparisons, one must bear in mind that the original (nonsubtracted) waveforms can be either positive or negative at each point, and thus a large difference in the subtracted waveform could arise from nonsubtracted activations that are equal in size but opposite in polarity. Therefore, the latency of differences in the brain response to different conditions can be directly inferred from these maps, but interpretation of how these differences arise requires reference to the nonsubtracted data.

The novel-minus-repeated differences were left-lateralized and localized to inferior ventral temporal regions, temporal pole, inferior prefrontal cortex, superior temporal sulcus, planum temporale, and occipitotemporal junction, in that temporal order 


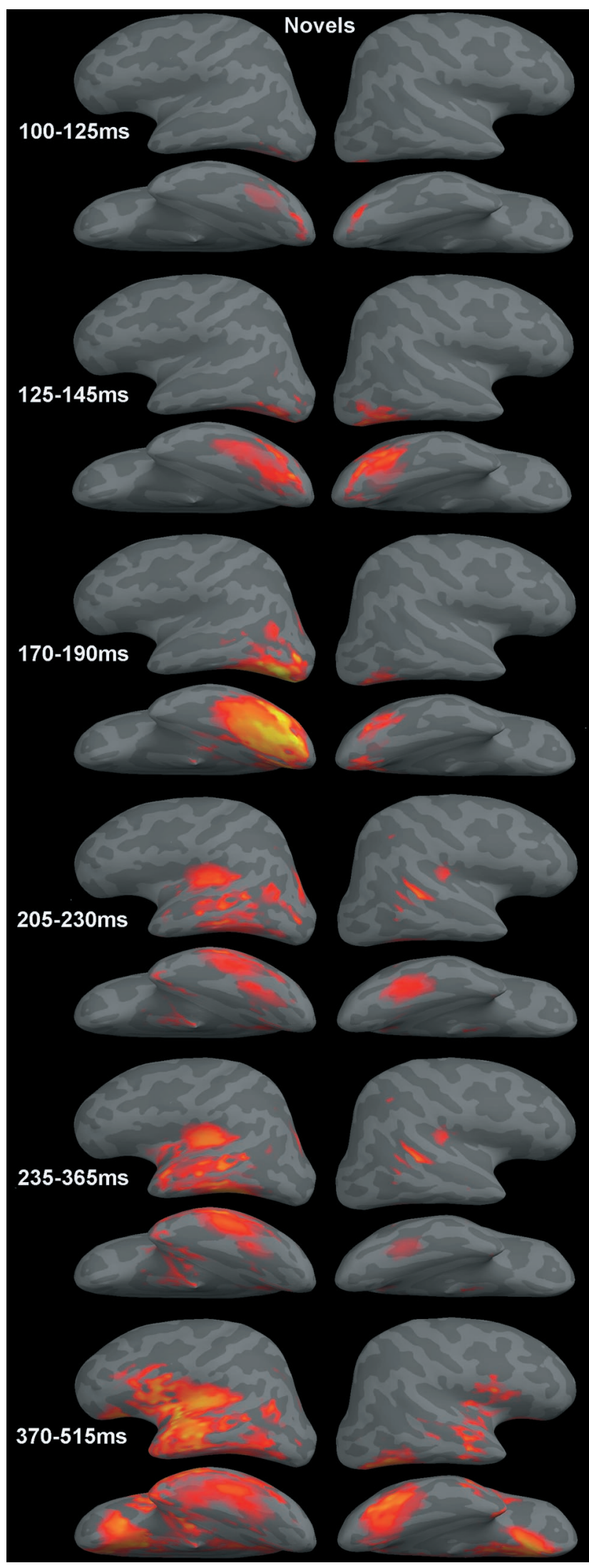

Figure 2. Estimated cortical activity patterns at different latencies after reading word stems. Activation begins with a bilateral visual response in posterior occipital cortex (100-125 msec) and subsequently spreads forward in ventral occipital cortex $(125-145 \mathrm{msec})$ and lateralizes to the left
(Fig. 3). Some areas strongly activated by the novel and repeated word stems, notably in the occipital lobe, showed no significant repetition effect. That is, the effects of repetition were concentrated in more anterior cortical areas and appeared anatomically selective for a subset of areas activated during word-stem completion.

The earliest significant repetition-associated differences appeared in left posteroventral temporal cortex (centered in the lateral occipitotemporal sulcus) at $\sim 200 \mathrm{msec}$ after stimulus onset and reflected greater activation to repeated word stems (Fig. 3, left). The next phase of the repetition effect was considerably later (from $\sim 365$ to $500 \mathrm{msec}$ ) (Fig. 3, right) and in the opposite direction. The responses were greater to novel word stems, moving from the temporal pole to inferior prefrontal regions by $\sim 420$ msec and to superior temporal regions by $\sim 455 \mathrm{msec}$. Medial frontal activation peaked at $\sim 445 \mathrm{msec}$ and decreased with repetition (data not shown). Activity remained strong in the above regions and was greater to novel word stems until $\sim 500 \mathrm{msec}$.

Finally, from $\sim 510 \mathrm{msec}$ onward, activation began to fade in lateral regions of the cortex and temporal pole. The differential response shifted to inferior ventral temporal cortex, in which it was stronger to repeated word stems until $\sim 530 \mathrm{msec}$, after which all differential activity became minimal.

\section{Activation at individual sites}

Figures 2 and 3 show snapshots of the estimated activity over the entire lateral and ventral aspects of the cortical surface at selected moments in time. An alternative method for visualizing activation is to plot the normalized estimated dipole strength at selected locations at all latencies (Fig. 4). These time courses support the same general points made by the movies: (1) the posterior occipital lobe was activated with a short latency and equally for novel and repeated word stems; (2) slightly more anterior occipital sites showed later activation, which peaked at $\sim 165 \mathrm{msec}$ and did not change with repetition; (3) posteroventral temporal sites (centered within the lateral occipitotemporal sulcus) showed an early increased activity to repeated word stems; (4) the planum temporale responded at approximately the same time but did not show a repetition effect until later, when it responded more to novel word stems; and (5) the anterior temporal lobe and (6) the inferior frontal gyrus were the last areas to be engaged and showed larger responses to repeated word stems.

\section{DISCUSSION}

MEG was used to map the spatiotemporal orchestration of brain regions involved in the generation of words to visually presented word stems and their modification during repetition priming. As summarized in Table 1, the response during novel word-stem completion followed a posterior-to-anterior sequence with distinct spatiotemporal stages. The earliest activation was in the occipital pole, followed by the anteroventral occipital cortex. Activation subsequently spread to a region at or near classically defined Wernicke's area, as well as portions of the ventral temporal cortex, then to anterior temporal and prefrontal cortex near classically defined Broca's area, and finally to medial frontal$$
\leftarrow
$$

hemisphere (170-190 msec). It then spreads to both posteroventral and lateral temporal areas $(205-230 \mathrm{msec})$ and then progressively involves anterior temporal (235-365 msec) and ventral prefrontal (370-515 msec) cortices, before fading after $515 \mathrm{msec}$. Dynamic statistical parametric maps (see Materials and Methods) show the maximal activation during the indicated period. 


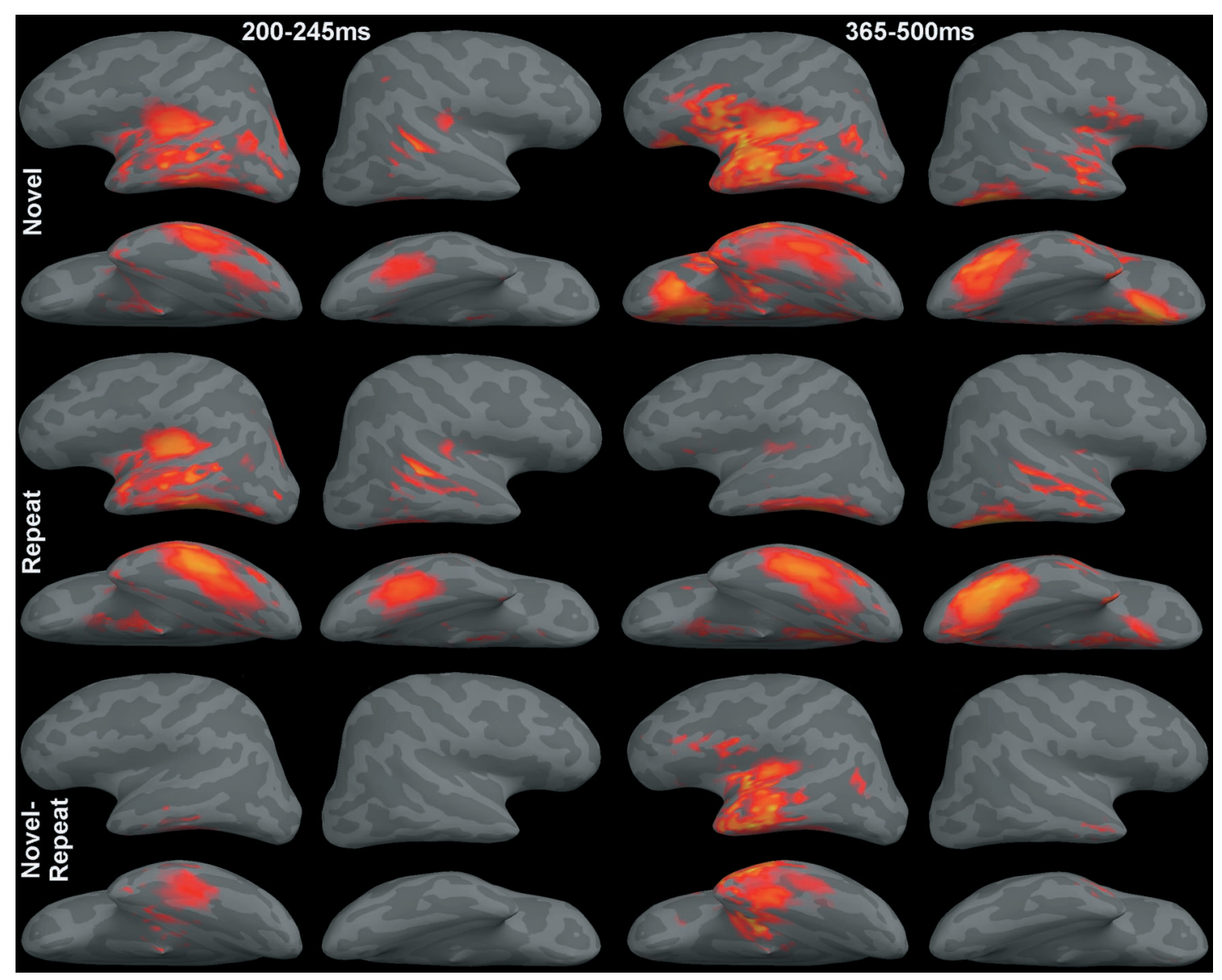

Figure 3. Repetition effects. The earliest differential activation (in favor of repeated word stems) is estimated to lie in left ventral temporal cortex between 200 and $245 \mathrm{msec}$. Later differential activation (larger to novel word stems) occurs at 365-500 msec, mainly in anterior temporal, inferior prefrontal cortex, and the planum temporale.

cortex. Thus, the earliest area to be activated was cortex, which has been shown to contain retinotopic representations of foveal vision (Sereno et al., 1995), whereas the last area was within cortex associated with late phases of verbal response production (Penfield and Roberts, 1959; Fiez and Petersen, 1998). The timing of activation, from visual processing to Wernicke's and then Broca's areas, provides a striking consistency with the major components of classical models of language processing (Geschwind, 1965; Benson, 1979). In addition, activation in ventral occipital and temporal areas extends the results of previous neuroimaging studies, suggesting that these regions have an important role in language processing.

\section{Classical language areas}

Between 200 and $500 \mathrm{msec}$, there was strong activity in and near Wernicke's area; from $\sim 370 \mathrm{msec}$ onward, there was also activity in and near Broca's area. The activation in Wernicke's area involved what would, in other contexts, be considered to be auditory association cortex. Although the current results do not identify the process performed by this area, similar activation has been found in other studies in which words are generated in response to visually presented letter strings (Frith et al., 1991; Demonet et al., 1992; Raichle et al., 1994; Menard et al., 1996; Buckner et al., 2000). These findings lend support to a core assumption of classical language models: that auditory (or perhaps polymodal) association cortex in the posterior superior temporal region participates in the encoding of visually presented stimuli associated with word or word-like forms.

Late activation near Broca's area suggests that it may participate in the late stages of word production. Neuroimaging studies with PET, fMRI, iERPs, and MEG have found activation in this region even when no overt or covert verbal response was required (Halgren et al., 1994b; Buckner et al., 2000; Dale et al., 2000). It appears that the left posteroventral prefrontal cortex may be involved in the manipulation of higher-level language representations that are temporally extended and occur late in the act of word production (for review, see Gabrieli et al., 1998; Smith et al., 1998; Ungerleider et al., 1998), perhaps to guide response selection (Thompson-Schill et al., 1999).

\section{Visual association cortex}

Subsequent to initial localization within the occipital pole, activation rapidly spread to ventral anterior occipital cortex. A variety of neuropsychological, neurophysiological, and neuroimaging data in humans and animals identify this region as part of the ventral visual pathway used in the processing of visual stimuli as objects (Ungerleider and Mishkin, 1982; Ungerleider and Haxby, 1994; Farah, 1995). Evidence for wordform-specific activation in this area has been found with iERPs (Nobre and McCarthy, 1995), MEG (Salmelin et al., 2000), and hemodynamic imaging (Petersen and Fiez, 1993). The response observed in the current study was initially bilateral at $\sim 125-145 \mathrm{msec}$ and then clearly 


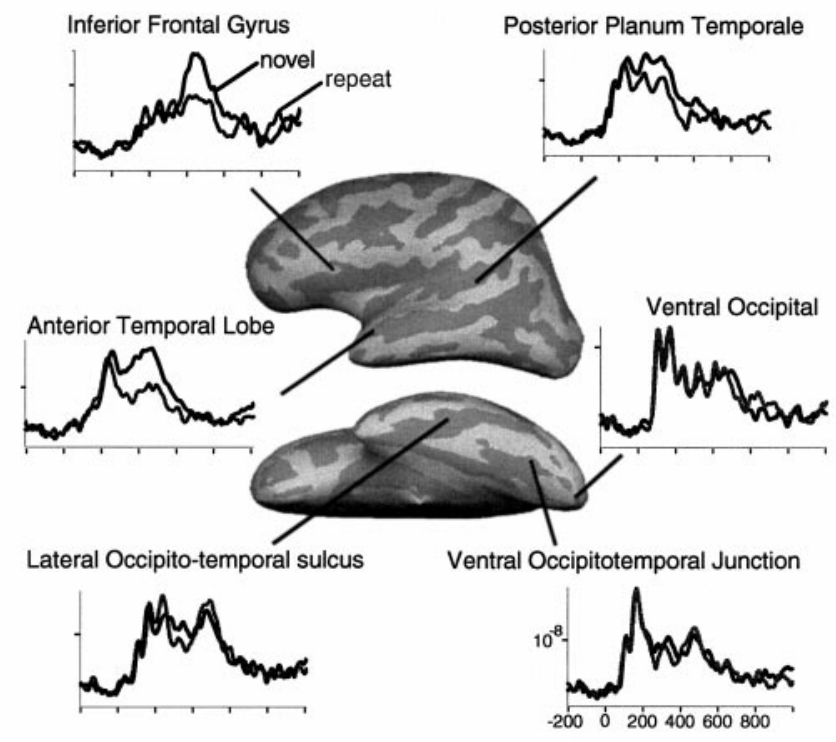

Figure 4. Time courses for selected location. Occipital regions are activated early and do not change with repetition, whereas more anterior regions activate later and show strong repetition effects.

2lateralized to the left hemisphere at $\sim 165-190 \mathrm{msec}$. The later activation is occurring in a location anterior to the retinotopic visual areas (Tootell et al., 1998) and at a time closely following their recruitment (Regan, 1989). In addition, previous iERP studies have reported a language or word-form-specific negativity at similar latencies within the ventral anterior occipital cortex (Nobre et al., 1994; Allison et al., 1999).

A similar activation is observed with faces and has been suggested to embody a material-specific encoding stage (Halgren et al., 1994a, 2000; Allison et al., 1999; Haxby et al., 2000). Together with these previous results, the current study suggests that word stems may pass through a specific encoding stage in the left ventral occipitotemporal cortex from $\sim 165$ to $190 \mathrm{msec}$, mediating between earlier visual and later cognitive processing; this process is likely associated with learned word forms.

\section{Posteroventral temporal cortex}

At the same time that activation spreads from the putative wordform area to Wernicke's area, it also spreads to left posteroventral temporal cortex, including parts of the fusiform and inferior temporal gyri. Electrical stimulation of this area has been found to produce profound and specific language deficits (Burnstine et al., 1990; Luders et al., 1991). The location of this activation, just anterior to the putative word-form area in inferotemporal cortex, and the timing of this activation, just after the putative word-form activation (beginning $\sim 200 \mathrm{msec}$ after word stem presentation onset), are both consistent with this activation supporting visual access to the lexical representations. Some models suggest that highly familiar words are preferentially processed through direct visual access (for review, see Humphreys and Evett, 1985; Caplan, 1990). This may correspond to the current observation that the left posteroventral activation was much larger in response to repeated word stems. Consistent with this speculation, a recent fMRI study found that well-learned mirror-reversed words also evoked increased activation in what appears to be the same area (Poldrack et al., 1998). However, repeated normal whole words do not always evoke increased activation in this area (Dale et al., 2000). These data suggest that this area may be especially invoked when, after sufficient training, word-like stimuli (i.e., reversed words or word stems) come to automatically evoke a lexical representation.

\section{Anterior temporal cortex}

Prominent activation was also observed in the anterior temporal lobe, with an onset latency longer than Wernicke's or posteroventral temporal areas. Like Broca's area, anterior temporal activation decreased in response to repeated word stems. These repetition-induced decreases were maximal from $\sim 365$ to 500 msec, corresponding in location and timing to a previous MEG-

\begin{tabular}{lllll}
\hline \multicolumn{2}{l}{ Table } \\
Figure & Lummary of MEG responses: novel word stems & \\
\hline $1 A$ & $100-125$ & Bilateral & Occipital pole & Putative function \\
$1 B$ & $125-145$ & Bilateral & Ventroanterior occipital & Foveal retinotopic cortex \\
$1 C$ & $165-190$ & Left & Ventroanterior occipital & Visual form processing \\
$1 D$ & $205-230$ & Left & Planum temporale, superior temporal sulcus & Word-form processing \\
$1 D$ & $205-230$ & Left & Lateral occipitotemporal sulcus language processing in juxta-auditory cortex \\
& & & Planum temporale, superior temporal sulcus, & Visual language processing in visual association cortex \\
& & & lateral occipitotemporal sulcus, anterior & Coactivation of phonemic, othographic, lexical, and \\
$1 E$ & $235-365$ & Left & temporal lobe & semantic areas \\
$1 F$ & $370-515$ & Left & Above plus posteroventral prefrontal cortex & Coactivation of above areas with response selection \\
\hline
\end{tabular}

\section{Table 2. Summary of MEG responses: effects of repetition}

\begin{tabular}{|c|c|c|c|c|c|c|}
\hline Figure & Latency & Laterality & Location & Greater to & ERP & Putative function \\
\hline 2 & $200-245$ & Left & Lateral occipitotemporal sulcus & Repeated & $\mathrm{N} 220$ & $\begin{array}{l}\text { Preferential word-form processing to } \\
\text { repeats }\end{array}$ \\
\hline 2 & $365-500$ & Left & $\begin{array}{l}\text { Temporal pole }(365 \rightarrow) \text {, inferior } \\
\text { prefrontal }(420 \rightarrow) \text {, superior } \\
\text { temporal }(455 \rightarrow)\end{array}$ & Novel & N400 & $\begin{array}{l}\text { Integrating potentially meaningful } \\
\text { stimuli with the cognitive context }\end{array}$ \\
\hline
\end{tabular}


fMRI study of repetition priming to visually presented words (Dale et al., 2000). Furthermore, anteroventral temporal iERP responses to words are also sensitive to repetition (Smith et al., 1986; Halgren et al., 1994a) and semantic priming (Nobre et al., 1994). The repetition-induced decline in Broca's area has been observed previously with PET and fMRI (for review, see Buckner et al., 2000), as well as with iERP.

Frontotemporal activation at $\sim 400 \mathrm{msec}$ in language tasks appears to correspond to the scalp-recorded, event-related potential component termed the N400 (Dale et al., 2000). The N400 is evoked by potentially meaningful stimuli, such as words and faces, and is modulated by the "ease" of integrating the stimulus with a cognitive context (for review, see Rugg, 1987; Kutas and Van Petten, 1988; Halgren, 1990). The amplitude of this response is attenuated by stimulus repetition, as was the anteroventral temporal and posteroventral prefrontal activation in the current study. These studies suggest that the N400, and thus the associated anteroventral temporal activation, embody supramodal cognitive integration at the semantic level (Damasio et al., 1996).

\section{Spatiotemporal integration in visual language processing}

In summary, the current study found a progression of activation during word-stem completion, beginning bilaterally in the occipital pole and then shifting to ventral occipital cortex. Activity quickly lateralized to the left anterior occipital cortex and then spread to ventral and dorsal posterior temporal areas, followed by anterior temporal and finally posteroventral prefrontal cortex. In the final stage, there was sustained coactivation of all of the above areas, with the exception of posterior occipital cortex. This sustained activation may permit multiple sources of lexical information (i.e., phonemic, orthographic, and semantic) to converge (possibly within Broca's area) and constrain verbal response selection.

In the current study, the sustained activation to novel word stems was greatly abbreviated and attenuated when they were repeated. That is, the early repetition-induced increase in posteroventral temporal cortex was followed by a widespread decrease in frontotemporal cortex. It is tempting to infer that repeated presentation allows word stems to directly activate lexical representations without involving widespread integrative mechanisms.

\section{REFERENCES}

Allison T, Puce A, Spencer DD, McCarthy G (1999) Electrophysiological studies of human face perception. I. Potentials generated in occipitotemporal cortex by face and non-face stimuli. Cereb Cortex 9:415-430.

Benson DF (1979) Aphasia, alexia, and agraphia. New York: Churchill Livingstone.

Binder JR (1997) Neuroanatomy of language processing studied with functional MRI. Clin Neurosci 4:87-94.

Buckner RL, Raichle ME, Petersen SE (1995) Dissociation of human prefrontal cortical areas across different speech production tasks and gender groups. J Neurophysiol 74:2163-2173.

Buckner RL, Koutstaal W, Schacter DL, Rosen BR (2000) Functional MRI evidence for a role of frontal and inferior temporal cortex in amodal components of priming. Brain 123:620-640.

Burnstine TH, Lesser RP, Hart Jr J, Uematsu S, Zinreich SJ, Krauss GL, Fisher RS, Vining EP, Gordon B (1990) Characterization of the basal temporal language area in patients with left temporal lobe epilepsy. Neurology 40:966-970.

Caplan D (1990) Neurolinguistics and linguistic aphasiology: an introduction. Cambridge, UK: Cambridge UP.

Dale AM, Sereno MI (1993) Improved localization of cortical activity by combining EEG and MEG with MRI cortical surface reconstruction: a linear approach. J Cognit Neurosci 5:162-176.

Dale AM, Fischl B, Sereno MI (1999) Cortical surface-based analysis. I. Segmentation and surface reconstruction. NeuroImage 9:179-194.
Dale AM, Liu AK, Fischl BR, Buckner RL, Belliveau JW, Lewine JD, Halgren E (2000) Dynamic statistical parametric mapping: combining fMRI and MEG for high-resolution imaging of cortical activity. Neuron 26:55-67.

Damasio H, Grabowski TJ, Tranel D, Hichwa RD, Damasio AR (1996) A neural basis for lexical retrieval. Nature 380:499-505.

Demonet JF, Chollet F, Ramsay S, Cardebat D, Nespoulous JL, Wise R, Rascol A, Frackowiak R (1992) The anatomy of phonological and semantic processing in normal subjects. Brain 115:1753-1768.

deMunck JC (1992) A linear dicretization of the volume conductor boundary integral equation using analytically integrated elements. IEEE Trans Biomed Eng 39:986-990.

Farah MJ (1995) Visual agnosia. Cambridge, MA: MIT.

Fiez JA, Petersen SE (1998) Neuroimaging studies of word reading. Proc Natl Acad Sci USA 95:914-921.

Fischl B, Sereno MI, Dale AM (1999) Cortical surface-based analysis. II. Inflation, flattening, a surface-based coordinate system. NeuroImage 9:195-207.

Frith CD, Friston KJ, Liddle PF, Frackowiak RS (1991) A PET study of word finding. Neuropsychologia 29:1137-1148.

Gabrieli J, Poldrack R, Desmond J (1998) The role of left prefrontal cortex in language and memory. Proc Natl Acad Sci USA 95:906-913.

Geschwind N (1965) Disconnexion syndromes in animal and man. Brain 88:237-294.

Halgren E (1990) Evoked potentials. In: Neuromethods, Vol 15, Neurophysiological techniques: applications to neural systems (Boulton AA, Baker G, Vanderwolf C, eds), pp 147-275. Clifton, NJ: Humana.

Halgren E, Baudena P, Heit G, Clarke JM, Marinkovic K (1994a) Spatio-temporal stages in face and word processing. I. Depth-recorded potentials in the human occipital, temporal, and parietal lobes. J Physiol (Paris) 88:1-50.

Halgren E, Baudena P, Heit G, Clarke JM, Marinkovic K, Chauvel P (1994b) Spatio-temporal stages in face and word processing. II. Depthrecorded potentials in the human frontal and Rolandic cortices. J Physiol (Paris) 88:51-80.

Halgren E, Raij T, Marinkovic K, Jousmaki V, Hari R (2000) Cognitive response profile of the human fusiform face area as determined by MEG. Cereb Cortex 10:69-81.

Hamalainen MS, Ilmoniemi RJ (1984) Interpreting measured magnetic fields of the brain: estimates of current distributions. Helsinki: Helsinki University of Technology.

Hamalainen MS, Sarvas J (1989) Realistic conductivity geometry model of the human head for interpretation of neuromagnetic data. IEEE Trans Biomed Eng 36:165-171.

Hamalainen M, Hari R, Ilmoniemi RJ, Knuutila J, Lounasmaa OV (1993) Magnetoencephalography: theory, instrumentation, and application to noninvasive studies of the working human brain. Rev Mod Phys 65:413-497.

Haxby JV, Hoffman EA, Gobbini MI (2000) The distributed human neural system for face perception. Trends Cogn Sci 4:223-233.

Howard D, Patterson K, Wise R, Brown WD, Friston K, Weiller C, Frackowiak R (1992) The cortical localization of the lexicons. Brain 115:1769-1782.

Humphreys GW, Evett LJ (1985) Are there independent lexical and nonlexical routes in word processing? An evaluation of the dual-route theory of reading. Behav Brain Sci 8:689-740.

Hunt SMJ (1994) MacProbe: a Macintosh-based experimenter's workstation for the cognitive sciences. Behav Res Methods Instrum Comput 26:345-351.

Kutas M, Van Petten C (1988) Event-related brain potential studies of language. In: Advances in psychophysiology (Ackles PK, Jennings JR, Coles MGH, eds), pp 139-187. Greenwich, CT: Jai.

Liu AK, Belliveau JW, Dale AM (1998) Spatiotemporal imaging of human brain activity using fMRI constrained MEG data: Monte Carlo simulations. Proc Natl Acad Sci USA 95:8945-8950.

Luders H, Lesser RP, Hahn J, Dinner DS, Morris HH, Wyllie E, Godoy J (1991) Basal temporal language area. Brain 114:743-754.

Meijs JWH, Peters MJ (1987) The EEG and MEG: using a model of eccentric spheres to describe the head. IEEE Trans Biomed Eng 34:913-920.

Meijs JWH, Bosch FGC, Peters MJ, Lopes da Silva FH (1987) On the magnetic field distribution generated by a dipolar current source situated in a realistically shaped compartment model of the head. Electroencephalogr Clin Neurophysiol 66:286-298.

Menard MT, Kosslyn SM, Thompson WL, Alpert NM, Rauch SL (1996) Encoding words and pictures: a positron emission tomography study. Neuropsychologia 34 185-194.

Nobre AC, McCarthy G (1995) Language-related field potentials in the anterior-medial temporal lobe. II. Effects of word type and semantic priming. J Neurosci 15:1090-1098.

Nobre AC, Allison T, McCarthy G (1994) Word recognition in the human inferior temporal lobe. Nature 372:260-263.

Ojemann JG, Buckner RL, Akbudak E, Snyder AZ, Ollinger JM, McKinstry RC, Rosen BR, Petersen SE, Raichle ME, Conturo TE (1998) Functional MRI studies of word-stem completion: reliability across 
laboratories and comparison to blood flow imaging with PET. Hum Brain Mapp 6:203-215.

Oostendorp TF, Van Oosterom A (1992) Source parameter estimation using realistic geometry in bioelectricity and biomagnetism. In: Biomagnetic localization and 3D modeling (Nenonen J, Rajala HM, Katila T, eds), report TKK-F-A689, pp 71-86. Helsinki: Helsinki University of Technology.

Penfield W, Roberts L (1959) Speech and brain mechanisms. Princeton, NJ: Princeton University.

Petersen SE, Fiez JA (1993) The processing of single words studied with positron emission tomography. Annu Rev Neurosci 16:509-530.

Petersen SE, Fox PT, Posner MI, Mintun M, Raichle ME (1988) Positron emission tomographic studies of the cortical anatomy of single-word processing. Nature 331:585-589.

Petersen SE, Fox PT, Posner MI, Raichle ME, Mintun MA (1989) Positron emission tomographic studies of the processing of single words. J Cognit Neurosci 1:1153-1170.

Petersen SE, Fox PT, Snyder AZ, Raichle ME (1990) Activation of extrastriate and frontal cortical areas by visual words and word-like stimuli. Science 249:1041-1044.

Phelps EA, Hyder F, Blamire AM, Shulman RG (1997) FMRI of the prefrontal cortex during overt verbal fluency. NeuroReport 8:561-565.

Poldrack RA, Desmond JE, Glover GH, Gabrieli JD (1998) The neural basis of visual skill learning: an fMRI study of mirror reading. Cereb Cortex 8:1-10.

Pujol J, Vendrell P, Deus J, Kulisevsky J, Marti-Vilalta J, Garcia C, Junque C, Capdevila A (1996) Frontal lobe activation during word generation studied by functional MRI. Acta Neurol Scand 93:403-410.

Raichle ME, Fiez JA, Videen TO, MacLeod A-MK, Pardo JV, Fox PT, Petersen SE (1994) Practice-related changes in human brain functional anatomy during nonmotor learning. Cereb Cortex 4:8-26.

Regan D (1989) Human brain electrophysiology: evoked potentials and evoked magnetic fields in science and medicine. New York: Elsevier.

Rugg MD (1987) Dissociation of semantic priming, word and non-word repetition effects by event-related potentials. Q J Exp Psychol 39:123-148.
Salmelin R, Helenius P, Service E (2000) Neurophysiology of fluent and impaired reading: a magnetoencephalographic approach. J Clin Neurophysiol 17:163-174.

Schacter DL, Alpert NM, Savage CR, Rauch SL, Albert MS (1996) Conscious recollection and the human hippocampal formation: evidence from positron emission tomography. Proc Natl Acad Sci USA 93:321-325.

Sereno MI, Dale AM, Reppas JB, Kwong KK, Belliveau JW, Brady TJ, Rosen BR, Tootell RB (1995) Borders of multiple visual areas in humans revealed by functional magnetic resonance imaging. Science 268:889-893.

Smith EE, Jonides J, Marshuetz C, Koeppe RA (1998) Components of verbal working memory: evidence from neuroimaging. Proc Natl Acad Sci USA 95:876-882.

Smith ME, Stapleton JM, Halgren E (1986) Human medial temporal lobe potentials evoked in memory and language tasks. Electroencephalogr Clin Neurophysiol 63:145-159.

Squire LR, Ojemann JG, Miezin FM, Petersen SE, Videen TO, Raichle ME (1992) Activation of the hippocampus in normal humans: a functional anatomical study of memory. Proc Natl Acad Sci USA 89:1837-1841.

Thompson-Schill SL, D'Esposito M, Kan IP (1999) Effects of repetition and competition on activity in left prefrontal cortex during word generation. Neuron 23:513-522.

Tootell RBH, Hadjikhani NK, Mendola JD, Marrett S, Dale AM (1998) From retinotopy to recognition: fMRI in human visual cortex. Trends Cogn Sci 2:174-183.

Ungerleider LG, Haxby JV (1994) "What" and "where" in the human brain. Curr Opin Neurobiol 4:157-165.

Ungerleider LG, Mishkin M (1982) Two cortical visual systems. In: Analysis of visual behavior (Ingle DJ, Goodale MA, Mansfield RJW, eds), pp 549-586. Cambridge, MA: MIT.

Ungerleider L, Courtney S, Haxby J (1998) A neural system for human visual working memory. Proc Natl Acad Sci USA 95:883-890. 